\title{
Evolución de los mensajes publicitarios de Hispano Suiza, desde su nacimiento hasta su colectivización
}

\author{
Carmen López de Aguileta Clemente I caguileta@uvigo.es
}

UNIVERSIDAD DE VIGO

Resumen: El éxito alcanzado por la marca de automóviles española Hispano-Suiza no fue una casualidad, sino por el contrario fue consecuencia de factores tan distintos y dispares como la filosofía empresarial adoptada por la compañía desde su fundación o el estallido de la primera guerra mundial, entre otros muchos.

Tomando como fuente los anuncios publicitarios, muchos de ellos inéditos, realizados por la marca española desde su nacimiento, en 1904, hasta el estallido de la guerra civil, éstos nos conducirán a través de la evolución histórica de la empresa automovilística española más internacional. Además, el análisis descriptivo de los mensajes utilizados en su publicidad también nos permitirán conocer cuáles fueron los valores presentes en la compañía y esgrimidos como argumentos por la misma.

Palabras clave: Hispano Suiza, historia, publicidad, automóvil, mensajes publicitarios.

Abstract: The success of the Spanish car brand Hispano-Suiza was as diverse as business philosophies adopted by the company since its foundation.

The corpus based study of advertising pieces, many of them unpublished, from the company from 1904 to 1936 - year of the outbreak of the Spanish Civil War - will lead us through the company's historical evolution, being Hispano Suiza the most international enterprise of the automotive sector in Spain. In addition, the descriptive analysis of the messages and topics used in the campaigns will highlight the values of the company and its importance as advertising arguments.

Key words: Hispano Suiza, history, advertising, car advertising. 


\section{Hipótesis, objetivos y metodología}

Los años transcurridos durante el primer tercio del siglo en España estuvieron marcados por importantes acontecimientos, nacionales e internacionales, como la primera guerra mundial, la segunda república española o la guerra civil, entre otros, los cuales dieron paso a una gran inestabilidad política y social. Sin duda alguna, la neutralidad española durante la gran guerra mundial y la enorme conflictividad laboral que se vivió en nuestro país durante los últimos años de la década de los veinte, afectaron de manera muy significativa a la evolución histórica de la empresa automovilística española más importante, Hispano Suiza.

El éxito y la proyección internacional alcanzados por esta marca nos animó a adentrarnos en su historia y a realizar un viaje en el tiempo, de más de un siglo, a través de su publicidad. Tomando como punto de partida la afirmación realizada en el libro Historia del consumo en España. Una aproximación a sus orígenes y primer desarrollo, "el análisis de la publicidad y el consumo permite evidenciar y expresar más allá del propio mensaje y objeto, presentando las situaciones y los conflictos sociales más de fondo" (Alonso, L. E. y Conde, F. 1994: 79), nos planteamos que la publicidad realizada por Hispano Suiza caminaría pareja al propio devenir histórico de la compañía, y su estudio nos permitiría conocer no sólo los momentos más relevantes y significativos para la marca, sino también otros aspectos como la resolución gráfica adoptada en cada ocasión. Así mismo consideramos que el análisis de sus mensajes debería acercarnos al sentir de la empresa, en los diferentes momentos que atravesó, e incluso a otras situaciones y circunstancias que se produjeron durante esos años.

El artículo se enmarca en el periodo comprendido entre los años 1904 y 1936, que se corresponde con la fundación de la compañía y la colectivización de la misma como consecuencia del estallido de la guerra civil española, respectivamente. Además ese periodo también fue el más importante, desde el punto de vista publicitario, para la marca, pues los años de la guerra civil, de la posguerra y el largo periodo de autarquía se caracterizaron por importantes carencias consecuencia de la situación de escasez, hambre y racionamiento que se vivió en todo el país, que dejaron escaso margen para cuestiones como la publicidad.

Tras una primera fase en la que se llevó a cabo una exhaustiva documentación, bibliográfica y audiovisual, acerca de la historia de Hispano Suiza, así como de la situación que atravesó la incipiente industria española de la automoción durante ese periodo. Posteriormente, se realizó un vaciado publicitario hemerográfico, fundamentalmente de revistas especializadas, prensa deportiva y prensa diaria, que nos ha permitido obtener un corpus de piezas publicitarias de Hispano-Suiza, algunas de ellas inéditas, cercano al centenar. Finalmente el análisis de los anuncios y carteles localizados nos permitió constatar, no sólo, la evolución gráfica de los mismos sino también el desarrollo gradual de los mensajes y de los valores que en ellos destacaba la marca. 


\section{Introducción}

El 14 de julio de 1904, se fundaba en Barcelona "La Hispano-Suiza, Fábrica de Automóviles S.A." de la mano de los industriales catalanes Damian Mateu i Bisa, Francisco Seix y otros inversores, con un capital social de 500.000 pesetas. En el transcurso de unos pocos años Hispano Suiza alcanzó un enorme éxito y prestigio, tanto dentro como fuera de nuestras fronteras, que no ha conseguido igualar, desde entonces, ninguna otra marca automovilista española hasta la fecha.

La filosofía que presidió en la compañía, desde el mismo momento de su constitución, estuvo encaminada a lograr una explotación a gran escala que le permitiese conseguir una estructura empresarial más fuerte para competir a todos los niveles:

(...) el buen éxito de la empresa habrá de hallarse por modo positivo en una explotación en mayor escala, a fin de que sin aumento sensible de los gastos generales del negocio logre una mayor producción, que abaratando el coste de los automóviles, facilite el sostenimiento frente a la competencia extranjera y deje un sobrante líquido remunerador. (Lage Marco, M. y GonzálezCuevas J. A. 2006:62) 1.

La política empresarial adoptada por la marca desde su fundación y el buen trabajo llevado a cabo por su ingeniero Birkigt en un breve pero intenso lapso de tiempo, entre otros, fueron factores claves del éxito y del reconocimiento que alcanzó Hispano Suiza a nivel internacional.

Frente a la debilidad empresarial y la fragilidad económica que caracterizaba a la mayor parte de las iniciativas automovilísticas españolas de aquellos primeros años, la fortaleza empresarial de Hispano-Suiza, desde su nacimiento, le permitió, no sólo, competir con las más importantes marcas extranjeras, sino que también le proporcionó la resistencia económica necesaria para aguantar durante los duros años que vivió el sector en España al comienzo de la década de los años veinte.

En muy pocos años y de la mano del ingeniero suizo Birkigt, los motores de los hispanos alcanzaron un importante desarrollo mecánico que situaron a la marca al mismo nivel técnico que las más destacadas compañías automovilísticas europeas de la época como Peugeot, Bugatti, Mercedes, Alfa Romeo, etc. Sin duda alguna, esta circunstancia contribuyó a incrementar el prestigio de la marca y en muy pocos años, sus automóviles se situaron entre los más rápidos, los más elegantes y los más resistentes del mundo.

La constatación de la dureza de los motores y de las mecánicas de los Hispano Suiza llegó, en una primera instancia, de la mano de los éxitos deportivos, posteriormente, durante la primera guerra mundial la fortaleza y fiabilidad que demostraron los motores hispano aplicados a la aviación convirtieron a la marca en una referencia a nivel mundial. En este contexto, la evolución de la empresa y su proyección hacia el exterior pronto se vieron

\footnotetext{
${ }^{1}$ La filosofía de Hispano-Suiza aparece recogida en el folleto memoria que la empresa editó con motivo de su constitución y del que se hacen eco Lage y González Cuevas.
} 
reflejadas en su publicidad y, en apenas veinticinco años, ésta evolucionó de forma muy significativa sus mensajes y la resolución gráfica de la misma.

En 1936, el estallido de la guerra civil española prácticamente dio al traste con Hispano Suiza y su proyección internacional. Y aunque la compañía continuó con cierta actividad cualquier rastro de publicidad desapareció por razones obvias.

Durante la contienda de 1936 las fábricas españolas de Hispano Suiza fueron colectivizadas pasando su gestión a depender de los comités de trabajadores. Concluida la guerra y debido al aislamiento internacional de nuestro país y a la práctica imposibilidad de obtener los suministros adecuados, fue sumamente dificultoso reiniciar la actividad industrial, que se centró en la fabricación de vehículos industriales, camiones y autocares por ser la necesidad prioritaria del país. Con la creación del INI el Estado decidió entrar en el campo de la automoción creando la empresa Nacional ENASA a la que se traspasaron las fábricas de HISPANO-SUIZA y sus actividades industriales. (Web Hispano Suiza 2009).

Con la guerra civil no sólo cesaron todas las ventas de automóviles, sino que además la mayor parte de los que existían se incautaron para reconvertirlos y ser utilizados durante el conflicto, y por supuesto se perdieron todas las inversiones que se habían realizado durante muchos años.

\begin{abstract}
Quien dude de la simbología del automóvil haría bien en mirar fotos de los primeros días de la guerra civil española, coches y más coches, arriba y abajo. El incautarse automóviles llegó a ser una obsesión, y estos circulaban sin parar por las calles de muchas ciudades con las siglas del "incautador" pintadas en sus flancos, con milicianos armados dentro y fuera del coche, en los estribos y en los guardabarros. Pronto se agotaban los depósitos de gasolina, pero fue cuestión de horas el emitir unos bonos de gasolina... hasta que ésta se agotó en las gasolineras. (Gimeno, P. 1993: 45).
\end{abstract}

Los años de la posguerra fueron muy difíciles, el conflicto dejó a la mayor parte de los sectores destrozados y sumidos en la penuria, y el de la automoción no se escapó a sus efectos. La política de racionamiento impuesta se extendió a casi todos los ámbitos de la vida cotidiana limitando el acceso a muchos productos. En este contexto, la situación económica y social no dejaba mucho margen para la publicidad.

\begin{abstract}
La guerra civil, pues, supuso un corte general en la vida y en el desarrollo de nuestro país, afectando de lleno al mundo descrito y, por tanto, al mundo del consumo, tanto en lo referido a la capacidad y dimensiones simbólico-motivacionales (...) el triunfo franquista en la guerra civil hizo retornar al primer plano de la actualidad social, cultural, política, una ideología fuertemente nacionalista que impregnó en estos años, como no podía ser por menos, la vida comercial y la escasa actividad publicitaria de las empresas del país. (Alonso, L y Conde, F. 1994:82-119).
\end{abstract}

Posteriormente, la década de los cuarenta y primeros años de los cincuenta, estuvieron marcados por el final de la segunda guerra mundial, afectando también a las formas de vida y consumo. En este contexto, la mayor parte de la industria española tardó más de una década en iniciar la recomposición y reestructuración de un nuevo tejido industrial.

La situación reinante en todo el territorio no dejó de verse reflejada en la publicidad de la época afectando de lleno tanto a la cantidad como al estilo de la misma. La mayor parte de los mensajes que existían hablaban, fundamentalmente y de forma indirecta, de las 
extremas dificultades de la vida, viéndose especialmente reflejadas en determinados productos como por ejemplo el gasógeno consecuencia de la falta de gasolina. En consecuencia, fue necesario que transcurriesen algunos años para que la actividad empresarial y publicitaria española recuperase el ritmo de los años previos a la guerra civil.

\section{Evolución publicitaria de Hispano Suiza}

\subsection{Primeros mensajes publicitarios: la marca y sus modelos}

La localización geográfica de Hispano Suiza en Cataluña y la afición de Ramón Casas ${ }^{2}$ por los automóviles, ligó a la marca con el arte y la publicidad desde su mismo nacimiento, al recibir Casas el encargo de diseñar las primeras acciones que se emitieron de la empresa por valor de 250.000 pesetas.

Desde el mismo instante de la constitución de la compañía la dirección técnica recayó en la persona del ingeniero suizo Marc Birkigt ${ }^{3}$. La experiencia atesorada por Birkigt, en otras iniciativas automovilísticas previas, le permitió el diseño de un automóvil de forma casi inmediata, de modo que antes del finalizar el año había conseguido fabricar y vender dos coches, uno de $10 \mathrm{cv}$. y otro de 14/16 cv. La principal novedad que aportaban los automóviles diseñados por Birkigt era la incorporación de los "chasis acorazados", que consistían en que el motor y el cambio formaban un solo bloque, ambos estaban acoplados perfectamente al chasis y unidos a éste a lo largo de sus laterales, ello aportaba una mayor rigidez del conjunto que formaban chasis y motor y rellenaba el espacio entre los largueros protegiendo el motor y todos los accesorios del polvo, barro, piedras, ...y otros elementos presentes en las pésimas carreteras españolas por aquellos años.

El "Sistema Birkigt", como lo denominó la propia empresa, fue inmediatamente patentado y utilizado como argumento publicitario en los primeros anuncios de Hispano-Suiza. El sistema desarrollado por Birkigt, para la protección de los chasis de sus automóviles, marcaba la diferencia con cualquier otro modelo existente en el momento. Esta circunstancia permitió a la marca utilizar una estrategia de diferenciación en sus primeros mensajes respecto a todas las demás, fundamentalmente frente a las extranjeras.

En 1904, el mismo año de la constitución de la sociedad, ésta insertaba su primer anuncio en la revista Mercurio (f.1). El original, a página completa, aparecía encabezado con el título "Automóviles acorazados sistema Birkigt con patente", a continuación un extenso texto

\footnotetext{
${ }^{2}$ Ramón Casas era uno de los máximos exponentes del modernismo en Cataluña y por ende en España, así como uno de los artistas más prestigiosos del momento. Además era un gran aficionado al automóvil por lo que mantenía una estrecha relación con el Real Automóvil Club de Cataluña desde su fundación en 1906. Su pasión le impulsó a ser uno de los artistas que introdujeron, de forma más temprana, el nuevo medio de locomoción en sus obras. Él mismo fue un pionero automovilista y un magnífico cronista del despertar industrial de Cataluña en la materia.

${ }^{3}$ El ingeniero Marc Birkigt procedía de las empresas de automóviles constituídas previamente por La Cuadra y J. Castro, en consecuencia aportaba una importante experiencia en la materia, acumulada durante su estancia en ellas. A su llegada a Hispano Suiza, Birkigt aplicó en ésta todo el conocimiento adquirido hasta ese momento, lo que le permitió desarrollar, de forma muy rápida, un avanzado sistema de chasis acorazado basado en los últimos proyectos que había llevado a cabo en la empresa J. Castro.
} 
explicativo compartía espacio con la imagen de un automóvil y la dirección de los talleres. En el anuncio Hispano-Suiza también hacía uso de su estatus de primera fábrica española, así como de la capacidad competitiva de sus automóviles, mediante frases como "No existen en el mundo mejores automóviles que los Hispano Suiza", o incluso mediante la utilización reiterada de la palabra "únicos" (f.1).

El mal estado en que se encontraban la mayor parte de las carreteras en nuestro país fue una constante en la publicidad de todos los anunciantes de automóviles, tanto nacionales como extranjeros. Esta circunstancia determinó, incluso, desarrollos mecánicos específicos por parte de los fabricantes para ellas. Por ello era habitual encontrar, sobre todo en los primeros años, frases en este sentido como: "especialmente construídos para las carreteras españolas" o "los únicos estudiados para las malas carreteras de España" (f.1).

El reconocimiento de la calidad de los automóviles Hispano-Suiza fue tan rápido que, en 1905 un año después de su constitución, la empresa firmaba el primer contrato de cesión de tecnología con la "Societé d'Automobiles à Genève" para la fabricación de "Hispanos" en todo el territorio de Suiza y en 1906 lo hacía con Italia. El prestigio que aportaba esta circunstancia fue inmediatamente utilizado como un nuevo argumento, tanto por la empresa como por sus agentes en diferentes anuncios (f.2, f.3). El 1 de febrero de 1906 Francisco Abadal, agente en Barcelona de la marca, publicaba un anuncio en la portada del diario El Mundo Deportivo que hacía referencia a las características de los chasis y también incluía, en un cuerpo superior, el dato relativo a las patentes en el extranjero, "Patentes vendidas en Suiza y en Italia" (f.3).

Ese mismo año la compañía ampliaba su oferta con dos nuevos modelos, el 20HP y el 30HP, y acudía por primera vez al Salón del Automóvil Club de Francia en París, y en 1907, presentaba el Tipo 6 o T60. En un breve lapso de tiempo había conseguido fabricar una gama completa de automóviles, y ello no tardó en verse reflejado en su publicidad. Aparecieron anuncios y carteles que se hacían eco de la gama completa, "Coches de 12, 20, 30, 40 y 60 caballos, ómnibus y camiones" señalaba un cartel de 1908 (f.5).

La mayor parte de la publicidad realizada por Hispano Suiza, durante los primeros años del siglo, no respondía a ninguna norma, ni teoría publicitaria establecida, pues como señalaba Prat Gaballí en su libro Una nueva técnica: La Publicidad Científica, éstas eran absolutamente desconocidas por los anunciantes españoles por aquellos años.

\begin{abstract}
La publicidad se ha reducido hasta hoy en España a una práctica comercial llevada a cabo sin más guía que las iniciativas individuales aisladas. Ni en la revista, ni en el libro, ni en la cátedra, hemos podido registrar antes de 1914 el más pequeño síntoma de que alguien conociera las modernas orientaciones de la publicidad o de que las estudiara e investigara (1917:9).
\end{abstract}

El carácter internacional que adquirió el automóvil desde su nacimiento, de la mano de la competición deportiva, favoreció la interrelación de las marcas existentes en los diferentes países. Esta circunstancia unida a otras, no menos importantes, como la presencia de 
importantes marcas extranjeras en suelo español desde las primeras luces del siglo como Renault, Dion Bouton o Darracq, entre otras, y la venta de automóviles importados influyeron de modo decisivo en la representación publicitaria que en España adoptaron las empresas automovilísticas existentes. En este contexto, el vacío teórico publicitario existente favoreció que las marcas españolas tomasen como referencia lo que estaban realizando las empresas automovilísticas extranjeras y lo aplicasen en la elaboración de sus anuncios y carteles en nuestro país. Esta situación provocó una importante evolución en toda la publicidad del sector en España en aquellos años, hasta el punto que éste se mostró pionero en la aplicación de técnicas y estrategias publicitarias que más tarde adoptarían otros productos (López de Aguileta, C. 2008: 608-611).

\subsection{Los años previos a la Primera Guerra Mundial}

A tenor de lo expuesto hasta el momento, es fácil entender que la mayor parte de la publicidad realizada por Hispano-Suiza, sobre todo durante la primera década del siglo y en los años previos a la primera guerra mundial, presentaba características poco habituales para la época. Nos referimos a aspectos como el tamaño, la colocación, la composición e incluso el contenido de sus mensajes. Frente a la mayor parte de la publicidad del momento que se caracterizaba por su reducido tamaño, debemos recordar que la utilización de anuncios a toda página, no fue habitual en España hasta los años veinte (Eguizábal Maza, R. 1998: 460), los anuncios de hispano presentaban, habitualmente, grandes formatos, algunos, incluso, a página completa. Respecto a la colocación o situación de los mismos, la característica más sobresaliente fue, sin duda alguna, la utilización de las portadas de las revistas y de los diarios para insertar sus anuncios, espacio habitualmente reservado a la información y por lo tanto poco empleado por el resto de los anunciantes en general.

Por lo que se refiere a la resolución gráfica y a la composición, la mayor parte de los anuncios presentaban un estilo muy similar. Incluían una imagen del chasis o del modelo, el nombre de Hispano Suiza, un breve y sencillo texto informativo y en algunas ocasiones el logotipo de la marca. Sin embargo, sus mensajes evolucionaron más rápidamente y, en un breve lapso de tiempo, pasaron a una fase más avanzada. De los sencillos textos iniciales, aparecidos en 1904 cuyo único objetivo era aportar información sin otra finalidad que dar a conocer la marca, el chasis Birkigt o la aparición de nuevos modelos, al final de la década comenzaron a surgir algunos anuncios que incluían mensajes más complejos. La madurez que había logrado la empresa, a pesar de sus pocos años de existencia, por un lado y el nivel de conocimiento en materia automovilística alcanzado por los compradores y aficionados, por otro, permitieron a la publicidad evolucionar y adoptar un tono diferente. Así asistimos a la aparición de anuncios que incluían mensajes más elaborados mediante la incorporación de un sinfín de detalles técnicos.

La publicidad realizada por Hispano en los últimos años de la primera década, además de hacer referencia a la extensa gama de modelos disponibles, también incluían nuevos conceptos y tecnicismos como; "carburador especial", "economía en el gasto de bencina", 
"rendimiento efectivo", "estabilidad", "souplesse", "motores de dos tiempos" (f.4), o "motores de tipo intensivo (f.5) entre otros. Los mensajes cambiaron radicalmente de tono, se trataba de un salto cualititativo muy importante, la publicidad se transformó de informativa en persuasiva, comenzando a intentar conquistar al comprador, a crear en él el deseo de tener ese automóvil. Hispano Suiza estrenaba una nueva etapa en la que su publicidad cumpliría una función bien distinta, la de conquistar al consumidor. En este sentido la marca española iniciaba lo que González Martín señala como la conquista del público: “.. Ja publicidad no fuerza ni obliga, sino que conquista, disminuyendo la inseguridad psicológica y el riesgo de toda conducta de compra" (1996: 207).

En 1910 Birkigt, desarrolló un chasis deportivo que presentó en el salón de París de ese mismo año. El nuevo vehículo fue bautizado con el nombre de Alfonso XIII, con el permiso del monarca español y obtuvo un éxito arrollador desde el mismo momento de su aparición. Con ese modelo surgió un nuevo concepto de automóvil, “ (...) con la aparición del HispanoSuiza Alfonso XIII nació el automóvil deportivo moderno" (Lage Marco, M, 2006, 18'30"), que se convirtió, inmediatamente, en el coche deportivo de referencia de toda Europa, trasladando a la marca un reconocimiento mundial.

Ese mismo año estallaba una huelga, de larga duración, en Barcelona que afectó de lleno a la producción de Hispano-Suiza. Las consecuencias de la misma no tardaron en hacerse sentir y la empresa comenzó a recibir anulaciones de pedidos nacionales e internacionales. Esta coyuntura propició la aprobación de la instalación de una fábrica Hispano-Suiza en Francia, muy cerca de París. El objetivo de la compañía era descentralizar la producción, y un año más tarde, en 1911 se constituía la "Société Française Hispano-Suiza". Por otro lado, el éxito comercial logrado hasta el momento aconsejaba el traslado de la fábrica española a unos locales más amplios, que se situaron en la calle Sagrera de Barcelona, abandonando definitivamente los de Floridablanca, como así lo atestiguan todos los anuncios aparecidos a partir de ese momento.

Durante los años previos al estallido de la primera guerra mundial, la actividad industrial de la marca fue enorme. Birkigt diseñó veintitrés vehículos y motores, todos incorporaban la más avanzada tecnología de su tiempo; motores de cuatro válvulas, compresores, doble árbol de levas en cabeza, doble encendido, cigüeñal de cinco apoyos, engrase a presión... situando a la marca entre las más reconocidas, y el prestigio de Hispano-Suiza se extendió a todos sus automóviles.

\subsection{Mensajes publicitarios de carácter deportivo}

La intensa y temprana participación deportiva de los automóviles Hispano Suiza en pruebas nacionales e internacionales, y los magníficos resultados obtenidos en la mayor parte de ellas generaron una gran cantidad de anuncios que se hacían eco de las victorias y hazañas deportivas de la marca. 
Sólo seis meses después de la creación de la empresa, en enero de 1905, un automóvil Hispano-Suiza conducido por Francisco Abadal conseguía el récord de la subida a la Rabassada. Esta primera victoria marcaría el inicio de un amplio y largo palmarés, lleno de triunfos que situaron a la marca en lo más alto de la competición internacional.

Ese mismo año, de la mano de las primeras victorias llegó el primer anuncio de carácter deportivo. Este se hacía eco de las primeras hazañas; "Récord de Cuesta de los Cuatro Caminos a Vista Rica, Récord de Valencia a Barcelona y Récord del kilómetro. Copa de los Pirineos un solo coche inscrito se clasifica y obtiene Medalla de Plata", en él también se hacia referencia a las patentes vendidas a países extranjeros, "patentes vendidas en Suiza y en Italia". En lo que respecta a la parte gráfica, destaca la incorporación de elementos modernistas en su composición como una figura femenina y diverso utillaje tipográfico. La imagen femenina, una automovilista, situada en un primer plano era la misma que un año antes había adornado las primeras acciones diseñadas por Ramón Casas para la compañía, en la composición también se hacía uso de orlas y filetes, y las tipografías, fundamentalmente las iniciales " $\mathrm{H}$ " y " $\mathrm{S}$ ", incorporaban formas redondeadas de tipo orgánico (f.2). Elementos todos ellos que denotaban claras influencias del Art Nouveau, y algunos como la figura femenina, era distintivo en las creaciones artísticas modernistas.

En 1908 un automóvil hispano lograba el primer premio de su serie en la carrera del Monte I gueldo, celebrada en San Sebastian. A partir de ese momento se multiplicaron los premios y los galardones conseguidos por automóviles Hispano Suiza, tanto en pruebas nacionales como en el extranjero. En 1910 el italiano Paolo Zuccarelli, a los mandos de un Hispano, vencía a los imbatibles Peugeot en la Copa de L'Auto en Francia, y ese mismo año los "voitasettes" Hispano se hacían con el triunfo en las competiciones de Mont-Ventoix, Monte Igueldo, Ostende y Boulogne, de este modo las victorias internacionales también comenzaron a estar presentes en el palmarés de la marca (f. 7).

En el transcurso de 1912, los hispano se alzaron con importantes y numerosos triunfos, tanto dentro como fuera de nuestras fronteras; el Campeonato de Amateurs de España, la Copa España, la Carrera en Cuesta del Guadarrama, la Côte de Saleye en Suiza, la Gran Copa del Zar de Rusia de 3.000 kilómetros, la Côte del Val de Suzon, la Challenge del Automóvil Club de la Picardie, la Côte de Mont Ventoux, Mitín du Mans, Mitín d'Anjoux, todos ellos en Francia, Côte Gilly en Suiza, Rouen en Ginebra, Gran Copa del Emperador de Alemania, Copa de Reims, Brooklands y la Copa de Italia. Los éxitos se sucedían, un año tras otro, quedando todo ello detalladamente reflejado y recogido en muchos y diferentes anuncios que aparecieron durante esos años en distintas publicaciones españolas, fundamentalmente en revistas del automóvil y en diarios deportivos de la época.

En plena efervescencia deportiva internacional el estallido de la primera guerra mundial paralizó, casi por completo, la competición europea, sin embargo la neutralidad española permitió continuar con la celebración de algunas pruebas de carácter nacional como la Copa 
Tibidabo o la Carrera de la Cuesta de Navacerrada, entre otras, según se constata en diversos anuncios localizados.

El extenso palmarés deportivo logrado por Hispano Suiza, consecuencia de la calidad mecánica de sus motores, dio "alas" a la empresa para crecerse, y los mensajes que hacían referencia a la supremacía de la marca comenzaron a adquirir presencia en su publicidad. Así durante los años 1914, 1915 y 1916 fue habitual encontrar anuncios que incluían un escueto pero contundente texto: "Los coches Hispano-Suiza han probado ya repetidas veces su enorme superioridad, su resistencia incomparable, la robustez de sus órganos" (f.8).

La mayor parte de los anuncios de carácter deportivo ofrecían un estilo muy similar. Casi todos estaban resueltos de forma muy sencilla, no incluían imágenes y se resolvían exclusivamente mediante sencillos textos que daban a conocer el puesto logrado en la prueba o las victorias conseguidas. Algunos adornaban sus textos con orlas, filetes y diverso utillaje tipográfico o sencillos elementos como laureles, columnas, etc. Pero, sin duda alguna, el rasgo más distintivo en ese tipo de anuncios de la marca española era que no incluían ninguna imagen, ni del automóvil ni de su piloto, a diferencia de otras marcas que sí lo hacían en los suyos.

3.4. La publicidad de Hispano Suiza durante la Primera Guerra Mundial y la posguerra.

En 1912 la fábrica de París ya superaba en producción a la de Barcelona, por ello un año más tarde se acordaba el traslado de la fábrica francesa a la población de Bois-Colombes. Al mismo tiempo se inició el estudio de la construcción de vehículos carrozados y del motor de aviación, pero en 1914 Francia entró en guerra y la fábrica situada en territorio francés tuvo que paralizar su producción. Las consecuencias de la guerra no se hicieron esperar, la demanda de motores se incrementó de forma considerable, y la paralización de la fábrica francesa obligaron a la fábrica de la Sagrera, en Barcelona, a triplicar su capacidad de fabricación (Hispano Suiza 2009). Las nuevas necesidades forzaron a Birkigt al desarrollo de un nuevo motor, que tras superar una dura prueba de resistencia logró la homologación por parte de Francia. Esta circunstancia supuso la construcción de aproximadamente 50.000 motores Hispano bajo licencia, por parte de catorce empresas francesas, una inglesa, una americana, tres italianas y una japonesa.

La continua demanda de motores y material bélico que el conflicto generaba empujó a Hispano Suiza a crear una nueva empresa y en 1917 se constituía “La Hispano Suiza Fábrica de Automóviles y material de guerra, S.A." con sede y fábrica en Guadalajara. En ese contexto, la compañía se vio obligada a postergar el desarrollo y la fabricación de motores para automóviles, durante algunos años. La propia dinámica industrial y publicitaria de la compañía estuvo más encaminada al desarrollo de material bélico y de transporte, y por lo tanto a la promoción de sus motores de aviación y de camiones, como así lo atestigua la mayor parte de la publicidad que apareció durante el periodo. 
Los argumentos más utilizados en los anuncios de esos años giraron entorno a la experiencia adquirida durante la guerra y a los valores logrados a lo largo de toda la década. Valores como "la velocidad, la regularidad, la resistencia, la seguridad y la economía" pero por encima de todos ellos se situaba la calidad, que no tardó en convertirse en un atributo de la marca. De este modo, la marca hizo extensivos esos valores en su publicidad a toda la gama de productos con frases como: "Vencedora en las grandes pruebas del Automovilismo Terrestre, Marítimo y Aéreo" (f.10).

El prestigio de Hispano-Suiza hacia años que había traspasado las fronteras, pero la perfección que lograron sus motores, como consecuencia de su especialización durante el conflicto, la situaron entre las mejores del mundo. La supremacía de la marca a nivel internacional fue plasmada por el caricaturista francés Bryan en la revista Automotive Industries. El artista sintetizó en un dibujo su visión de los automóviles Hispano-Suiza, durante su visita al salón del automóvil de París celebrado en 1919. El dibujo representaba la superioridad de los automóviles Hispano-Suiza, para lo cual situaba un enorme Hispano en el centro del dibujo, que empequeñecía y ensombrecía a todo lo que le rodeaba, tanto fueran automóviles de la competencia allí presentes, como al público asistente (f.9). Posteriormente ese dibujo fue utilizado como anuncio publicitario por la compañía en varias ocasiones y en diversas publicaciones españolas.

3.5. Los éxitos deportivos más internacionales, mensajes triunfalistas.

En 1919, Hispano-Suiza adoptó la imagen de una cigüeña para identificar sus vehículos, sustituyendo, desde ese momento, las dos alas extendidas el volante y la cruz, que habían conformado su logotipo durante años. El origen del nuevo emblema procedía del escudo que utilizaba la escuadrilla "Guynemer" de aviones de caza franceses equipados con motores Hispano-Suiza.

Concluída la contienda, la competición internacional recuperó, poco a poco, su ritmo normal y entre los años 1920 y 1923 los automóviles Hispano volvieron a clasificarse en los primeros puestos en las más prestigiosas carreras internacionales como la de Boulogne-sur-Mer. También obtuvieron otros importantes galardones como el Récord Mundial de Velocidad en el Aeródromo de Villasauvage, la Copa Deutsch en octubre de 1922, y el Gran Premio de Otoño disputado en Monza, entre otros. Pero, sin duda alguna el éxito más importante fue la victoria lograda en 1928 en Indianápolis, frente a STUTZ. La carrera estaba planteada con una duración de 24 horas pero concluyó por el abandono por una avería del STUTZ, que no pudo mantener el fuerte ritmo impuesto por el Hispano que marchó, en todo momento, en primera posición.

Todas y cada una de las victorias y hazañas deportivas logradas por la marca española fueron perfectamente recogidas y reflejadas en distintos anuncios, como se puede comprobar en la revisión de los mismos. Su consolidación a nivel internacional y los continuos éxitos deportivos obtenidos dotaron a toda la publicidad de la marca de un tono 
triunfalista que inauguró un nuevo camino. Comenzaron a surgir mensajes que dejaban entrever la satisfacción que imperaba en la compañia mediante la utilización de términos como “orgullo", "proeza”, “insuperables" y otros en esta misma línea.

3.6. El orgullo de Hispano Suiza a través de sus mensajes.

Tras la guerra, se vivieron buenos años para la industria automovilística mundial, configurando lo que se podría llamar la segunda etapa del automóvil. Se produjeron importantes cambios y avances mecánicos como; el doble encendido, la dirección suave, los frenos de varilla, los servofrenos mecánicos, los neumáticos de balón, el frenado doble, la iluminación eléctrica, etc., (Iglesias Scott, I. 2006: 36’57"). En España al concluir la guerra la industria de la automoción existente contaba con importantes marcas en activo, y aunque la situación laboral comenzaba a presentarse conflictiva, durante el primer salón del automóvil celebrado en Barcelona en 1919 estuvieron presentes más de nueve marcas. Sin embargo, esta situación duró poco tiempo más, en nuestro país, ya que en el salón de 1922 el número de marcas presentes había descendido y dos años más tarde, durante la celebración del tercer salón del automóvil de 1924 sólo quedaban activas Hispano Suiza y Elizalde.

El cambio tan radical en el rumbo de la industria de la automoción española se debió a la coexistencia, en un breve lapso de tiempo, de diversas circunstancias y factores que afectaron de lleno a la ya de por sí frágil y débil industria automovilística existente, abocándola a su práctica y definitiva desaparición. De una parte, una vez concluída la primera guerra mundial todos los países europeos adoptaron una serie de medidas arancelarias para proteger a sus industrias, gravando las importaciones de automóviles con elevados impuestos. Sin embargo en España el gobierno no sólo no adoptó ningún gravamen, sino que además promulgó un decreto de liberalización de las importaciones de automóviles, que favoreció el incremento de las ventas de automóviles de marcas extranjeras. Además, los continuos conflictos laborales y la inestabilidad social existente durante el periodo provocaron restricciones de crédito y una fuerte crisis financiera.

Para explicar parte de lo ocurrido en ese periodo, a continuación nos remitiremos a las palabras expresadas por José María Gallart Folch, consejero delegado de Hispano Suiza, en el informe incluído en la memoria "La industria del automóvil en España", publicado en Barcelona el 1 de marzo de 1924:

Todas las naciones extranjeras se han preocupado de cubrir esta industria con un arancel protector que haga en cada nación muy difícil, sino imposible, las ventas de marcas extranjeras; en cambio en España parecer no sólo haber olvidado esta cuestión, sino que despreciando el ejemplo de otros países, saltando por encima de sus propias leyes y reglamentos, se empeña en dejar abierto su mercado a todas las competencias extranjeras, anulando la vida de la industria nacional en esta materia y quedando tributaria del extranjero" (en Polo, E. 1996: 129-130). 
Las continuas quejas y la presión realizada, tras duros años, por las pocas marcas de automóviles que sobrevivieron finalmente fueron escuchadas, y después de años perdidos y muchas empresas cerradas, los gobernantes españoles comenzaron a adoptar las primeras medidas encaminadas a la protección de la industria automovilística nacional. En pocos años las disposiciones empezaron a dar sus frutos y en el salón del automóvil de Barcelona de 1927 se presentaron dos nuevas marcas nacionales, Ricart y Euskalduna.

Hispano Suiza atravesó un periodo marcado por una dicotómica situación. Por un lado, como acabamos de explicar, el mercado nacional automovilístico atravesó, durante esos años, una delicadísima situación que evidentemente afectaba a la empresa, pero por otro, el éxito logrado con sus motores durante el conflicto, fundamentalmente con los motores de aviación, habían convertido a la marca en un referente a nivel mundial.

En general, para la marca fueron años de orgullo y esplendor, ya que en un breve periodo de tiempo, había conseguido situar a sus automóviles entre los mejores del mundo y posicionar su marca como sinónimo de calidad. Además había tenido la capacidad de desarrollar determinados modelos como el Alfonso XIII o el H6, entre otros, que le permitían situarse al mismo nivel que las marcas más prestigiosas del momento, “(...) saliendo maravillas mecánicas como el H6, que se convirtió el rival directo del Rolls Royce "Silver Ghost" (Autos Clásicos 2009).

Aunque Hispano Suiza no realizó campañas publicitarias, tal y como las entendemos hoy en día, programadas en el tiempo y en los medios y atendiendo a determinadas estrategias, diríamos que en los últimos años de la década de los veinte aparecieron en algunos medios, nacionales e internacionales, diversos anuncios que presentaban un estilo y un tono muy afínes, pero diferentes a lo realizado hasta el momento en materia publicitaria por la compañía.

En general, se trataba de anuncios de imagen de marca que transmitían orgullo mediante la utilización de frases como "el motor de las proezas y los récords" o "Un orgullo nacional" (f.8). También recurrieron a valores como la calidad y el lujo con frases como "Automóviles de máxima calidad, la gran marca nacional" o "Coches de alta calidad". La calidad fue sin duda alguna el valor más importante para la marca y ésta no tardó en convertirse en un atributo de la misma, extendiéndose a todos sus productos.

En 1927 aparecía un anuncio, en diferentes publicaciones y momentos, que reflejaba perfectamente el espíritu de satisfacción imperante en la marca (f.12). Tras una excelente trayectoria y años de magníficos resultados deportivos de sus automóviles y de sus motores de aviación, Hispano Suiza había conseguido alcanzar una proyección y un reconocimiento internacional. Ese espíritu aparecía perfectamente reflejado en el anuncio en la frase “después de haber probado todos los coches de lujo, haga Vd. una prueba con el nuevo 6 cilindros, 20HP (...) Se trata de un coche no superado técnicamente, provisto de los último adelantos. Material insuperable garantizado". Junto a los valores anteriormente descritos, 
Hispano Suiza también se había ligado a otros que se movían en el entorno del lujo y la exclusividad, los cuáles también se vieron representados en el anuncio, a través de la resolución gráfica del mismo. En un primer plano se situaba la protagonista, una joven automovilista elegantemente vestida y con las iniciales HS bordadas en el pecho del traje, tras ella se podía contemplar la entrada de una suntuosa mansión que era sobrevolada por una bandada de cigüeñas, símbolo de la marca. Todos los elementos gráficos que conformaban la composición se movían en el ámbito de los valores de la elegancia, la distinción, el lujo ... y los textos se centraban en destacar los logros mecánicos y deportivos de la marca durante su existencia. De este modo ambos, texto e imagen, se complementaban y apoyaban, logrando un conjunto con gran fuerza expresiva y comunicativa.

Pero esto no era todo, el último párrafo del texto, además hacia referencia a las primeras medidas proteccionistas adoptadas por el gobierno en materia automovilística durante 1927: "Compre Vd. un 6 ó un 4 cilindros Hispano Suiza, no solamente por patriotismo -o para acogerse a las reducciones en las contribuciones, impuestos y arbitrios a que se refiere el R.D. de 9 de Abril del corriente año, relativo a los automóviles de fabricación nacional-; sino también porque no encontrará $\mathrm{Vd}$. mejor ni mejores condiciones en coche de buen gusto y calidad" (f.12). En resumen se trataba, probablemente, del anuncio o "campaña" más completo realizado por Hispano Suiza. Presentaba una resolución gráfica elegante y equilibrada, pero además abordaba a través de un texto breve, claro y conciso cuestiones tan dispares, pero tan importantes, como las ventajas técnicas presentes en los automóviles de la marca, la trayectoria deportiva internacional de sus vehículos y motores de aviación y por último las medidas fiscales adoptadas en 1927 a favor de la industria española de automoción.

En 1929 se celebraron dos importantes acontecimientos en España, por un lado tuvo lugar la Exposición Ibero-Americana en Sevilla y por otro la Exposición Internacional en Barcelona, en ambos casos Hispano-Suiza acudió con un stand donde hizo gala de su orgullo y realizó diverso material publicitario. Los años siguientes fueron años muy convulsos, marcados por una gran inseguridad social y económica, tanto dentro como fuera de España. El crack del 29, desencadenó una crisis a nivel mundial. En España la situación no fue diferente y la inestabilidad existente provocó continuas huelgas que impedían el desarrollo normal del trabajo. Esta coyuntura afectó directamente al tejido industrial, incluso las empresas más sólidas y fuertes, como Hispano-Suiza, que habían conseguido sobrevivir otros momentos difíciles, se tambalearon, viendo peligrar sus estructuras. La precaria situación se prolongó hasta que dio paso a la proclamación de la segunda república, la cual se extendió hasta el estallido de la guerra civil.

Habida cuenta de los buenos resultados que estaban produciendo las medidas de protección que sobre los automóviles había adoptado el gobierno en 1930, tanto sobre la economía como sobre la propia industria nacional, éste incrementó nuevamente los aranceles sobre la 
importación de vehículos extranjeros. La nueva disposición, se tradujo en un descenso inmediato de las importaciones que se redujeron más de un 75\%.

La mayor parte de los mensajes publicitarios de los años previos a la guerra civil apelaban, fundamentalmente, a la compra de automóviles de marcas españolas, hacían uso en su publicidad de argumentos ligados a la defensa de la industria nacional, al patriotismo e incluso a la reducción del precio de los automóviles nacionales frente a los de importación. La cuestión fue abordada por Hispano Suiza mediante la utilización de frases y mensajes como “La industria nacional, quiere y puede competir con la industria extranjera" o "No proteja V. Innecesariamente la industria extranjera" (f.11) entre otros.

\section{Conclusiones}

La historia de Hispano-Suiza se desarrolló en un breve pero intenso periodo de tiempo y la compañía pronto se sitúo entre las más importantes marcas automovilísticas del momento. Su prestigio y reconocimiento le llegó de forma muy temprana, en una primera instancia, gracias a las victorias deportivas logradas con los motores desarrollados por Birkigt y, más tarde, debido al éxito alcanzado por el desarrollo de sus motores de aviación durante la segunda guerra mundial. Los triunfos se sucedieron y la compañía no dudo en hacer uso de ellos como argumentos de peso en su publicidad, en unas ocasiones con un fin estrictamente informativo, pero en otras como un testimonio de su prestigio y calidad.

El análisis y lectura cronológica de los anuncios realizados por esta marca española permite, no sólo, la reconstrucción de una parte importante de su historia, sino también conocer detalladamente algunos acontecimientos y el preciso momento y modo en que éstos sucedieron. En este sentido, su publicidad se comportó como un diario iconográfico de la propia compañía.

La presencia de Hispano Suiza, desde su mismo nacimiento, en otros países como Francia, Italia, Suiza, etc., en ocasiones como consecuencia de la cesión de sus patentes y en otras debido a su participación deportiva en las diferentes pruebas internacionales influyó de forma innegable y palpable en su publicidad, tanto en lo que se refiere a la forma expositiva como compositiva de la misma. Al no tener referentes publicitarios en la materia en España, consecuencia del vacío teórico existente, las marcas automovilísticas españolas tomaron como referencia lo que estaban haciendo las firmas extranjeras en sus respectivos países, emulando lo que allí se hacía. Esta circunstancia influyó más tarde en el desarrollo de una parte importante de la publicidad que se realizó en España en otros sectores y productos.

Durante la primera década, la privilegiada situación económica y empresarial de la marca y los tempranos éxitos logrados por sus automóviles, le permitieron una pronta y rápida evolución publicitaria. Sus mensajes evolucionaron de informativos a persuasivos, para ello no dudó en recurrir a valores ligados fundamentalmente a la velocidad, fiabilidad, resistencia, dureza, y otros similares, estrechamente relacionados con la mecánica. 
Posteriormente, en la década de los años veinte, en general toda la publicidad evolucionó de forma significativa en España. Las primeras teorías en la materia y algunas importantes marcas extranjeras se asentaron en nuestro país, y de la mano de éstas también llegaron las primeras agencias publicitarias extranjeras. La publicidad de las diferentes marcas automovilísticas también se vio inmersa en esa transformación, quedando perfectamente plasmado en el caso de Hispano Suiza. En pocos años, sus anuncios evolucionaron de forma palpable, frente a la realizada durante los primeros momentos en la que la utilización de imágenes quedaba casi restringida a la presencia de un chasis o automóvil, y a información relativa al mismo, los años transcurridos tras la guerra aportaron un aire nuevo y renovado a la marca. De la mano del prestigio y reconocimiento alcanzado con sus motores de aviación durante el conflicto, la compañia se creció, y el orgullo y la satisfacción por el trabajo bien hecho invadió su publicidad. Posteriormente, mediada la década de los años veinte se dio paso a situaciones más complejas y aunque el espíritu de satisfacción seguía presente otros valores como la exclusividad, el lujo o la elegancia se convirtieron en sus protagonistas, viéndose representados de forma muy diversa. Durante los últimos años, aunque el orgullo continuó presente, el tono de los mensajes se tornó más preocupante, la competencia extranjera "invadió" prácticamente el mercado nacional aprovechando la ventajosa situación existente, entonces Hispano Suiza comenzó a apelar al patriotismo de los compradores y a la defensa de la industria nacional.

Por último lo que respecta a los soportes utilizados por la empresa para insertar sus anuncios en nuestro país, la mayor parte de ellos aparecieron en revistas deportivas y del automóvil como; el Diario Deportivo, El Sport, La Jornada Deportiva, Los Deportes, Stadium, España Automóvil, Automovilismo-Electricidad-Maquinaria, etc., aunque muchos de ellos también lo hicieron en los programas de las pruebas automovilísticas que se publicaban coincidiendo con las mismas. Publicaciones todas ellas dirigidas, en su mayor parte, a un público masculino que era el comprador y usuario mayoritario de los automóviles Hispano Suiza en aquellos años.

En consecuencia y tras lo expuesto hasta aquí podemos concluir que como habíamos previsto la publicidad de Hispano Suiza se comportó como lo que Ferrer Roselló denomina "altavoz y pregonero" (2006: 37) de lo sucedido en aquellos años, mediante el empleo de técnicas y estrategias de diversa naturaleza. El análisis cronológico de la misma nos ha permitido conocer una parte de su historia, así como los momentos más significativos y el sentimiento imperante en la compañía a lo largo de los años más importantes para la misma, contado de forma gráfica.

\section{RefERENCI AS Bı BLI OgRÁfi CAS y AUdi OVI SUALES}

Alonso LUIS EnRIQUe y CONDE Fernando (1994): “Historia del consumo en España: Una aproximación a sus orígenes y primer desarrollo". Madrid: Debate. 
Autos Clásıcos (2009): "La historia de Hispano Suiza", en http://autosclasicos. espaciolatino.com/historias/hispanosuiza.htm (consultado: 15/3/2009).

Eguizábal MaZA, Raúl (1998): Historia de la publicidad. Madrid: Eresma \& Celeste.

FERRER Roselló, Clemente (2006): Los nuevos valores de la publicidad. Madrid: Instituto Europeo de Marketing, Comunicación y publicidad.

Gimeno Valedor, Pablo (1993): El Automóvil en España. Su historia y sus marcas. Madrid: Real Automóvil Club de España.

GonZÁlez MARTín, José Antonio (1996): Teoría general de la publicidad. Madrid: Fondo de cultura económica de España.

Hispano Suiza (2009): Portal de Hispano Suiza, "Historia de la marca 1914" en http://www.lahispano-suiza.com/historia/index.htm (consultado: $13 / 1 / 2009)$

IgLESIAS SCOTT, Ignacio (2006) en España País de Automoción [Programa de televisión] Documental emitido por Canal Historia. Parte I- 12 de octubre, parte II - 19 de octubre.

LAge MARCo, Manuel (2003): Hispano Suiza en la Aeronáutica. Hombres, empresas, motores y aviones. Madrid: Editorial Empresarial.

LAGE MARCo, Manuel (2006): España País de Automoción [Programa de televisión] Documental emitido por Canal Historia. Parte I- 12 de octubre, parte II - 19 de octubre.

Lage Marco, Manuel y GonzÁlez-Cuevas, José Antonio (2006): Madrid La Rueda de la Historia. De los coches de caballos al centenario del Salón del Automóvil 1907-2006. Madrid: Fundación Instituto Tecnológico para la Seguridad del Automóvil.

LóPez de AgUiletA, Carmen (2008): La Publicidad del automóvil en España 19001936. Tesis doctoral. Universidad de Vigo. Facultad Ciencias Sociales y de la Comunicación.

Polo, Emilio (1996): Alfonso XIII y el Automovilismo. Madrid: Cie Dossat 2000.

Prat Gaballí, Pedro (1917): Una nueva técnica. La publicidad científica. Clases de enseñanza mercantil, Curso 1915-1916. Barcelona: Cámara de Comercio y Navegación de Barcelona.

Prat Gaballí, Pedro (1934): Publicidad Racional. Barcelona, Labor. 


\section{MÁGENES}

f. 1 (1904)

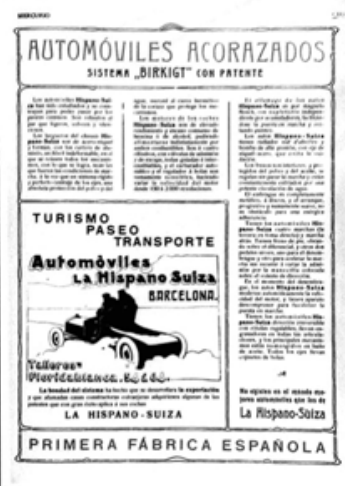

f. 4 (1908)

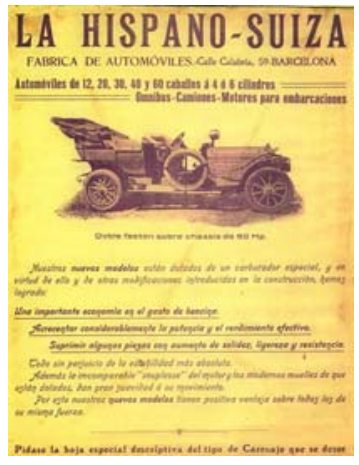

f.2 (1905)

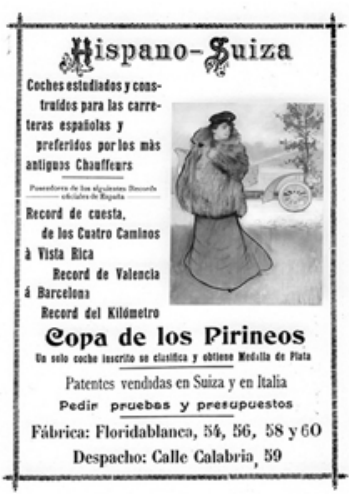

f.5 (1908)

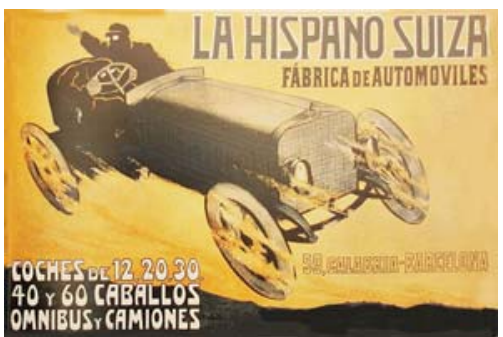

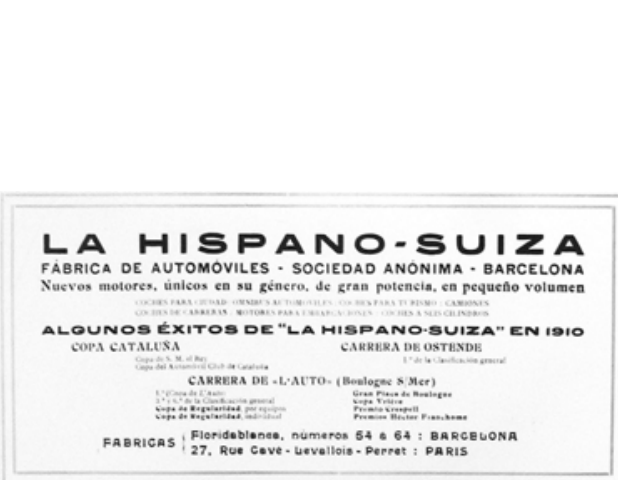
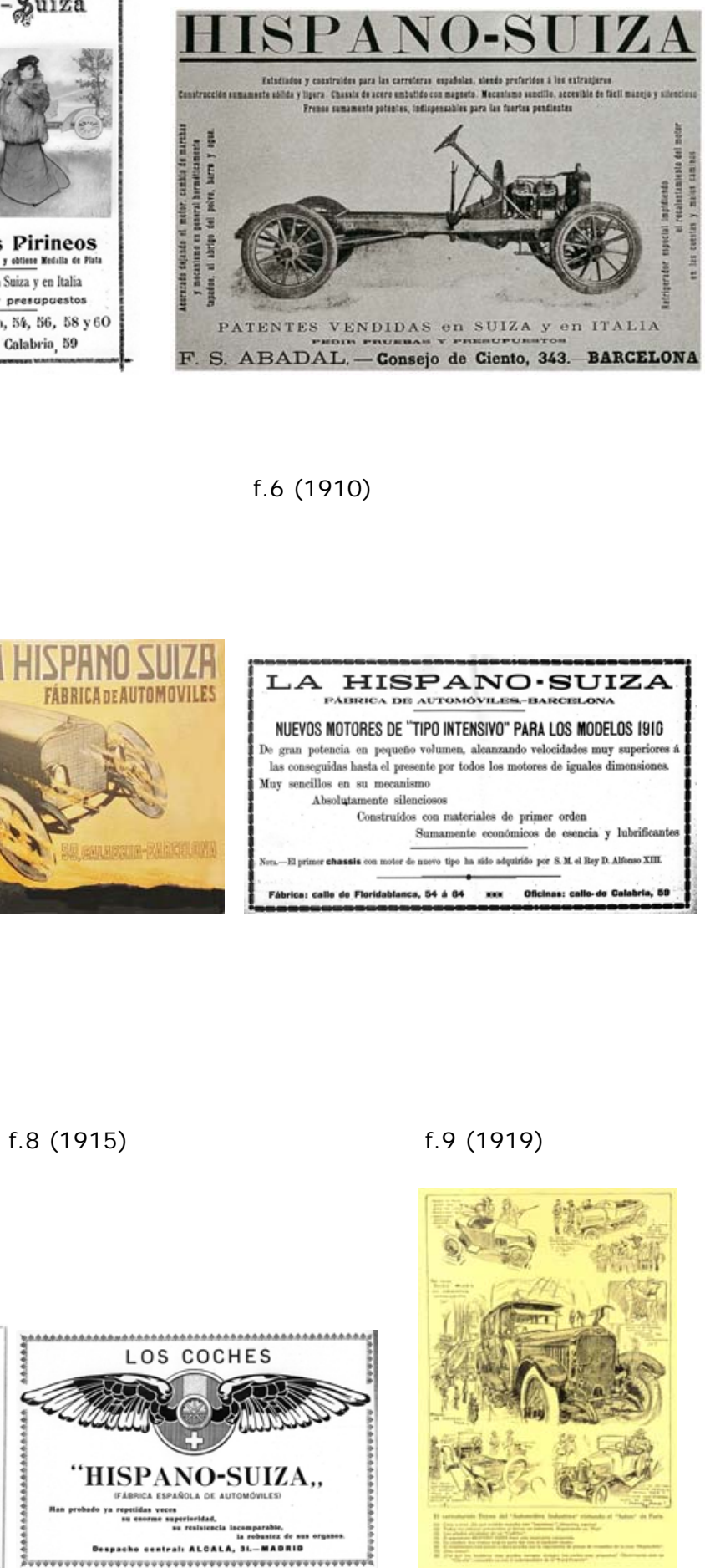

f. 6 (1910)
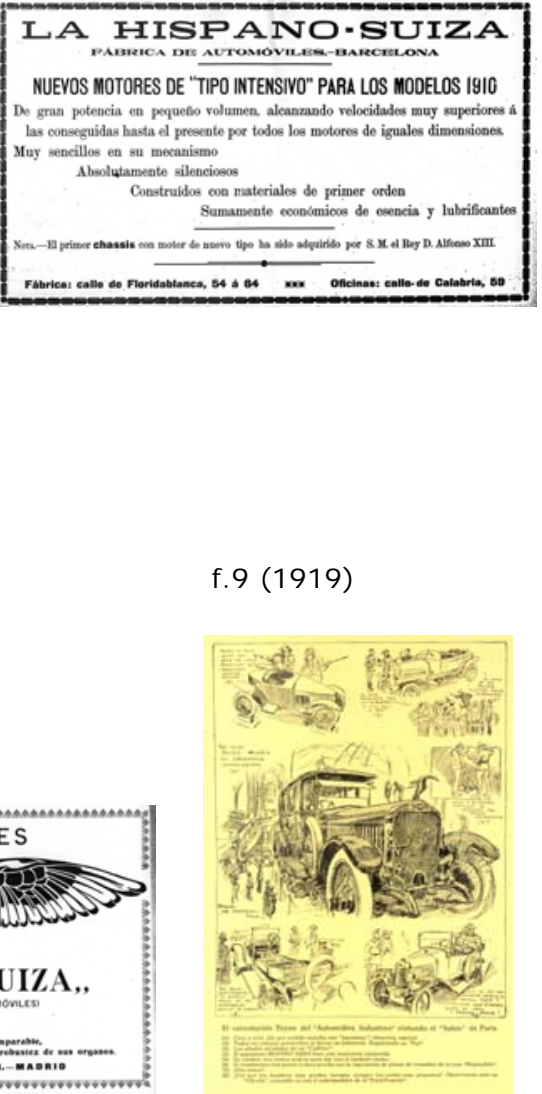
f. $10(1923)$

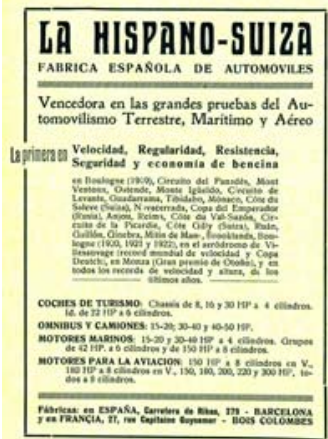

f.11 (1924)

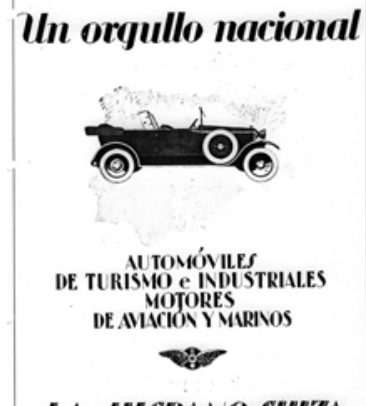

LA IIISPANO-SUIZA f.12 (1927)

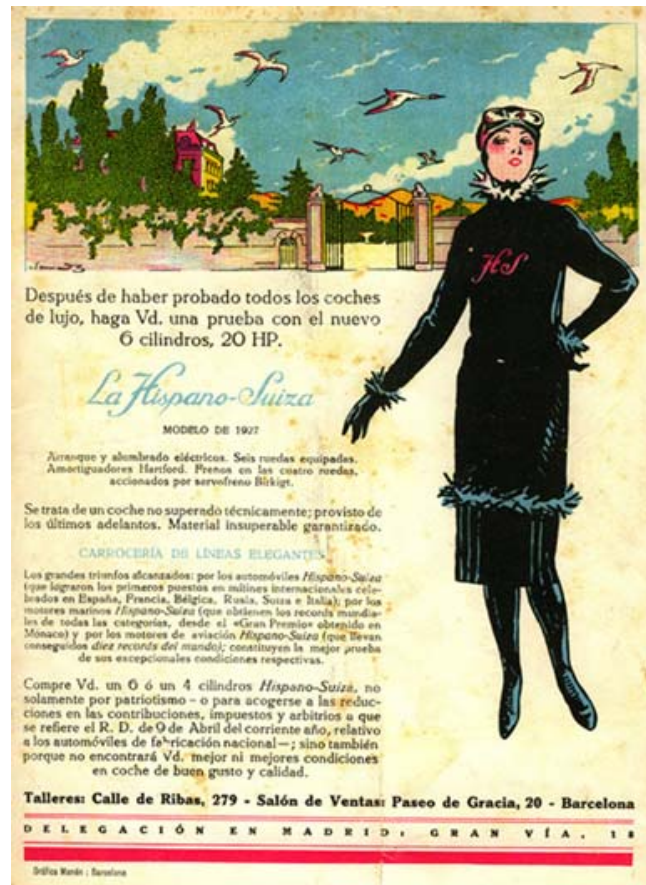

[Recibido: 10-03-2009. Aceptado (con necesidad de modificaciones): 03-2009. Recepción de la versión modificada: 17-05-2009] 